\title{
PRESERVANCE OF FUNCTIONAL CAPACITY IN OSTEOARTHRITIS KNEE IN RURAL AND SEMI-URBAN POPULATION
}

\author{
Banda Sreekanth Rao', Vutukuru Sri Ravindranath2, G. V. S. Moorthy³, T. Prasad ${ }^{4}$
}

${ }_{1}^{1}$ Assistant Professor, Department of Orthopaedics, Bhaskar Medical College Hospital, Yenkapally, Telangana, India.

2Professor, Department of Orthopaedics, Bhaskar Medical College Hospital, Yenkapally, Telangana, India.

3 Professor, Department of Orthopaedics, Bhaskar Medical College Hospital, Yenkapally, Telangana, India.

4Professor, Department of Orthopaedics, Bhaskar Medical College Hospital, Yenkapally, Telangana, India.

\section{BACKGROUND}

ABSTRACT

Osteoarthritis (OA), also often called 'osteoarthrosis' or 'degenerative joint disease,' is the most common form of arthritis. Prevalence of $\mathrm{OA}$ in India is reported to be in the range of $17-60.6 \%$. Knee osteoarthritis ${ }^{1}(\mathrm{OA})$ is a common condition, which represents a major contribution to the burden of physical disability. ${ }^{2} \mathrm{OA}$ is one of the most prevalent chronic diseases worldwide. ${ }^{3}$ Globally, hip and knee $\mathrm{OA}$ is ranked as the 11th highest contributor to global disability (measured by years lived with disability) and as the 38th highest in terms of overall burden (as measured by disability-adjusted life years) in $2010 .{ }^{4}$ Prevalence increases with age, so that about $11 \%$ of all women over the age of 60 years have symptoms due to knee $\mathrm{OA}$.

The aim of this study is to estimate the prevalence of OA knee to determine whether physical exercise, occupational modifications or NSAID medication constitutes a benefit or a risk in the development and progression of knee osteoarthritis in rural and semi-urban population.

\section{MATERIALS AND METHODS}

1. Questionnaire Development

The questionnaire was developed by the authors for the purpose of this study by using the current literature and input from content experts.

The questionnaire was reviewed by five orthopaedic surgeons and research methodologists for face and content validity.

2. Participant Screening

A total of 510 patients were screened for participation in this study, of which 110 were deemed ineligible to participate in the study.

3. Demographics

The majority of patients were females (66.9\%) and lived in semi-urban locations $(89.2 \%)$. Most patients made less than Rs. 200,000 annually (62.2\%) and did not have health insurance (89.3\%). Approximately, half of the patients had a comorbid disease at the time of the assessment (54.2\%). Common comorbidities included hypertension (38.8\%), diabetes (20.4\%) and osteoporosis $(12.8 \%)$.

\section{RESULTS}

A total of 510 patients were screened for participation in this study, of which 110 were deemed ineligible to participate in the study. The results were discussed in detail about the need for change in lifestyle, medical management and the physical methods.

\section{CONCLUSION}

Change in lifestyle, occupation and exercises helped the patients to avoid surgical intervention. Prevalence of osteoarthritis of knee was higher in females in semi-urban and rural areas than in men. This is also observed because of osteoporosis in menopause women, sedentary lifestyle, older age, less educated, and treated frequently with oral steroids.

\section{KEY WORDS}

Primary OA, Osteoporosis, Physical Methods, Steroids.

HOW TO CITE THIS ARTICLE: Rao BS, Ravindranath VS, Moorthy GVS, et al. Preservance of functional capacity in osteoarthritis knee in rural and semi-urban population. J. Evolution Med. Dent. Sci. 2018;7(28):3160-3165, DOI: 10.14260/jemds/2018/711

'Financial or Other Competing Interest': None.

Submission 07-05-2018, Peer Review 02-06-2018,

Acceptance 08-06-2018, Published 09-07-2018.

Corresponding Author:

Dr. Vutukuru Sri Ravindranath,

Professor,

Department of Orthopaedics,

Bhaskar Medical College Hospital,

Yenkapally-500075,

Telangana,

India.

E-mail: drravivutukuru@gmail.com

DOI: $10.14260 /$ jemds/2018/711

\section{(c) $($ ) $९$}

\begin{abstract}
BACKGROUND
Osteoarthritis is derived from Greek words "Osteo" meaning the bone, "Ortho" meaning joints and "Itis" which means inflammation. The clinical manifestations in $\mathrm{OA}$ are gradual development of joint pain, swelling, instability, stiffness and loss of motion. 5 The joints most commonly affected are the knees, hip and those of the hand and spine. OA has gradual onset and symptoms usually do not appear until around the age of 45 to 50 years. Evidences suggest that inflammation events are outcome of intervention of polymorphonuclear leucocytes that release lysosomal enzymes and oxygen free radicals. This results in increased articular cartilage destruction, joint pain, stiffness and limitation of movement. In $\mathrm{OA}$ subchondral osteoblasts have abnormal phenotype,
\end{abstract}


elevated alkaline phosphatase, increased release of osteocalcin, reduced parathyroid hormone and PGE2 dependent cAMP formation, elevated Urokinase plasminogen, IGF-1 and altered collagen metabolism. ${ }^{6}$ These disease cells produce more IL- 6 and PGE- 2 than normal. With improved health care facilities in developing countries, the elderly age population is also increasing. Thus, the volume of age related disease like osteoarthritis is expected to increase and shall demand health care priority. Pain and inflammations are important concerns both for patient and the doctor besides progressive nature of the disease. The main objectives in the management of $\mathrm{OA}$ are to reduce symptoms, minimise functional disability, limit the progression of structural changes and ultimately delay or avoid arthroplasty. "The best treatment for knee $\mathrm{OA}$ is prevention." It has been recently confirmed that in knee $\mathrm{OA}$, mechanical stress is the most important underlying mechanism. This is in contrast to hand $\mathrm{OA}$, where systemic processes appear to be most important. 5

A recently published cross-sectional analysis found that women also experience greater knee pain than men, regardless of Kellgren-Lawrence grade. ${ }^{6}$ Pain, inflammatory flares, stiffness and loss of movement and function represent major symptoms of $\mathrm{OA}$ including knee $\mathrm{OA}$, resulting in a substantial adverse impact on patient's quality of life and considerable economic burden.7,8,9 Secondary changes occurring in the joint with increasing age cause OA to be one of the major health problems in the elderly. In the epidemiological studies, the relationship between age and OA was found to be the most striking finding.?

\section{MATERIALS AND METHODS \\ Design}

Observational study.

Osteoarthritis of the knee is a highly prevalent condition among adults, characterised by the progressive destruction of the cartilage that lines the knee joints, the subchondral bone surfaces and synovium proliferation accompanied by pain, immobility, muscle weakness and reduction in function and the ability to perform activities of daily living. Two types of $\mathrm{OA}$ of the knee are recognised: the more prevalent primary $\mathrm{OA}$ of the knee is the result of the progressive joint cartilage destruction over time, whereas secondary OA of the knee can be caused by trauma, infections etc. In this study only first type, i.e. primary $\mathrm{OA}$ is taken into the study.

\section{Objective}

To estimate the prevalence of OA knee to determine whether physical exercise, occupational modifications, NSAID medication constitutes a benefit or a risk in the development and progression of knee osteoarthritis in rural and semiurban population.

\section{Inclusion Criteria}

1. Primary OA of knees.

2. Females above the age of 40 years.

3. Males above age of 50 years.

\section{Setting}

Bhaskar Medical College, Yenkapally.

\section{Participants}

The study was conducted in rural and semi-urban population areas of Moinabad district between February 2017 and February 2018 at Bhaskar Medical College. The sample comprised of 200 males and 200 females. A semi-structured interview scheduled was used to interview the study subjects.

\section{Main Outcome Measures}

The prevalence was found to be high in females in semiurban population associated with increased age, understanding, educational qualification, hysterectomy/ menopause, steroid injections, sedentary life, lack of exercises and duration of 10 - 20 years.

\section{Questionnaire Development}

The questionnaire was developed by the authors for the purpose of this study by using the current literature and input from content experts.

The questionnaire was reviewed by five orthopaedic surgeons and research methodologists for face and content validity.

This approach helped to ensure that all questions were worded adequately and were culturally relevant and appropriate. The questionnaire included a section that asks the patient how their knee osteoarthritis was managed in the past by medications, supplements, braces, physiotherapy etc.

\section{Demographics}

The mean age of the included patients was 58.6 years (Table 1).

The majority of patients were female (66.9\%) and lived in semi-urban locations (89.2\%). Most patients made less than Rs. 200,000 annually (62.2\%) and did not have health insurance (89.3\%). Approximately, half of the patients had a comorbid disease at the time of the assessment (54.2\%). Common comorbidities included hypertension (38.8\%), diabetes (20.4\%) and osteoporosis (12.8\%) Table 1.

\section{Medical History of the Affected Knee}

Patients presenting with knee pain had been experiencing pain for more than 1 year $(50.8 \%)$ (Table 2). Two-thirds of the study participants had bilateral knee pain (66.0\%). Over half of the patients $(60.3 \%)$ had been previously diagnosed with knee $\mathrm{OA}$ by a clinician and most had received this diagnosis within the past year $(60.2 \%)$. The prescription of oral medications was associated with younger age, the absence of deformities and lower K-L grades which is consistent with current treatment recommendations. ${ }^{6}$ Kellgren-Lawrence (K-L) grades 1 and 2 were most common with $30.0 \%$ and $28.1 \%$ of patients falling in these categories, respectively. Approximately, one-third of the patients had deformities of the knee (33\%) with $34.2 \%$ of all patients having a varus deformity.

The majority of patients used medical treatments. They were non-steroidal anti-inflammatory drugs $(72.0 \%)$ and topical agents (55.2\%). Patients from rural area took treatment by branding (5\%), local counter-irritants, massage (15\%) and oral steroids (12\%). 
Table 1, 2 and 3 describe the patient's characteristic, disease characteristics and pain level and functional limitation respectively.

Most of the patient's occupation was agriculture. They were increased activities of squatting, sitting cross legged, climbing of trees, digging ground and wells, prolonged standing and walking long distances. Women at house-hold and agriculture work were more prone to knee arthritis associated with menopause, local massage, uneducated, reduced understanding, oral steroids and comorbid conditions like thyroid, diabetes, hypertension and osteoporosis. Semi-urbans were more prone to OA, because of sedentary lifestyle. Patients addicted to alcohol and smoking had severe OA knee.

\section{Factors associated with Preservance of Function of Affected Knee}

Patients from rural areas occupation was agriculture. On initial phase of knee arthritis they received nonpharmacological treatments like branding, massage and local counter-irritants. Remission was for short period. On relapse responded well with NSAIDS prescribed by local practitioner and few received oral steroids.

Patients treated at our centre had longer duration of remission as they received NSAIDS, vitamins, chondroprotectives, calcium supplements, carbonate and citrate and osteoporosis medicine. Comorbid conditions were treated by respective specialist, physiotherapy electrotherapy, wax, exercises, postures, use of splints, ambulatory aids and gait training. The needy were given intra-articular steroid and viscosupplements. Osteoarthritis awareness counselling scheduled for patients helped them. Patients deferred surgery. $90 \%$ of patients were not having insurance policy, annual economy was 50,000 to 200,000 . Patients found practising physiotherapy, usage of splints, ambulatory aids, change of occupation, avoiding stressful activities, modification of activities of daily living like avoiding squatting or cross-legged sitting helped in preserving the joint function. Exercise is also beneficial as shown in a recently published randomised controlled trial in women with $\mathrm{OA}$ of the knee.10

\section{Table 1}

\begin{tabular}{|c|c|c|c|c|}
\hline \multirow{2}{*}{$\begin{array}{l}\text { Patient's Characteristic } \\
\qquad n=400\end{array}$} & \multicolumn{2}{|c|}{ Rural } & \multicolumn{2}{|c|}{ Semi-Urban } \\
\hline & $\begin{array}{l}\text { Male } \\
n=80\end{array}$ & $\begin{array}{c}\text { Female } \\
n=111\end{array}$ & $\begin{array}{l}\text { Male } \\
n=84\end{array}$ & $\begin{array}{c}\text { Female } \\
n=125\end{array}$ \\
\hline Age (yrs.) & $55.6 \pm 11.6$ & $52 \pm 10.5$ & $53.4 \pm 11.1$ & $51.5 \pm 10.3$ \\
\hline Body mass index $(\mathrm{kg} / \mathrm{m} 2)$ & $24.5 \pm 3.4$ & $25.6 \pm 3.6$ & $26.2 \pm 3.5$ & $27.4 \pm 3.2$ \\
\hline Income/Annum- No income & $03(3.6)$ & $30(27.02)$ & 0 & $98(78.4)$ \\
\hline Income/Annum $(\mathrm{Rs}<50,000$ & $40(50)$ & $76(41.4)$ & $22(26.2)$ & $20(16)$ \\
\hline Income/Annum 50,001-100,000 & $29(36.2)$ & $04(3.6)$ & $54(64.2)$ & $05(04)$ \\
\hline Income/Annum 100,000-200,000 & $11(13.75)$ & 0 & $10(11.9)$ & $02(1.6)$ \\
\hline \multirow{3}{*}{$\begin{array}{c}\text { Health Insurance None } \\
\text { Private } \\
\text { Government }\end{array}$} & $80(100)$ & 111(100) & $40(47.6)$ & $100(80)$ \\
\hline & 0 & 0 & $30(35.7)$ & $10(8)$ \\
\hline & 0 & 0 & $14(16.6)$ & $15(12)$ \\
\hline \multicolumn{5}{|l|}{ Comorbidity } \\
\hline None & 20 & 30 & 20 & 30 \\
\hline Hypertension & 35 & 40 & 38 & 42 \\
\hline Diabetes & 15 & 19 & 20 & 32 \\
\hline Osteoporosis & 10 & 30 & 11 & 40 \\
\hline Heart & 3 & 4 & 4 & 5 \\
\hline Lung & 4 & 1 & 3 & 3 \\
\hline Neurological & 2 & 2 & 4 & 6 \\
\hline Thyroid disorder & 2 & 9 & 3 & 15 \\
\hline Kidney & 5 & 2 & 5 & 4 \\
\hline Infection & 2 & 1 & 0 & 0 \\
\hline Cancer & 2 & 8 & 1 & 5 \\
\hline Coagulopathy & 0 & 0 & 0 & 0 \\
\hline Liver & 10 & 5 & 10 & 12 \\
\hline \multirow{4}{*}{$\begin{array}{l}\text { Addictions- } \\
\text { Tobacco } \\
\text { Smoking } \\
\text { Alcohol } \\
\end{array}$} & & & & \\
\hline & 20 & 12 & 30 & 05 \\
\hline & 18 & 2 & 20 & 2 \\
\hline & 32 & 18 & 22 & 10 \\
\hline \multirow{4}{*}{$\begin{array}{c}\text { Other joints with OA- No other OA } \\
\text { Lower back } \\
\text { Hand } \\
\text { Hip }\end{array}$} & 50 & 40 & 40 & 52 \\
\hline & 20 & 60 & 35 & 46 \\
\hline & 05 & 12 & 08 & 14 \\
\hline & 02 & 03 & 06 & 04 \\
\hline
\end{tabular}

Values are presented as mean \pm standard deviation or number (\%). 
Table 2. Disease Characters

\begin{tabular}{|c|c|c|c|c|}
\hline \multirow{2}{*}{$\begin{array}{c}\mathrm{n}=400 \\
\text { Duration of Knee Pain (yrs.) }\end{array}$} & \multicolumn{2}{|c|}{ Rural } & \multicolumn{2}{|c|}{ Semi-Urban } \\
\hline & $\begin{array}{l}\text { Male } \\
\mathbf{n}=80\end{array}$ & $\begin{array}{c}\text { Female } \\
\mathrm{n}=111\end{array}$ & $\begin{array}{l}\text { Male } \\
\mathrm{n}=84\end{array}$ & Female $n=125$ \\
\hline \multicolumn{5}{|l|}{ Affected knee } \\
\hline$<1$ & 55 & 75 & 59 & 82 \\
\hline $1-5$ & 15 & 20 & 15 & 31 \\
\hline $6-10$ & 06 & 10 & 07 & 06 \\
\hline$>11$ & 04 & 06 & 03 & 06 \\
\hline Left & 35 & 60 & 30 & 40 \\
\hline Right & 30 & 35 & 40 & 45 \\
\hline Bilateral & 15 & 16 & 14 & 30 \\
\hline \multicolumn{5}{|l|}{ Diagnosed with knee OA } \\
\hline Yes & 65 & 89 & 70 & 105 \\
\hline No & 15 & 22 & 14 & 20 \\
\hline \multicolumn{5}{|l|}{$\begin{array}{l}\text { Time since OA diagnosis (yrs.) } \\
\text { Kellgren-Lawrence grade }\end{array}$} \\
\hline$<1$ & 22 & 29 & 24 & 40 \\
\hline $1-5$ & 40 & 43 & 45 & 52 \\
\hline $6-10$ & 08 & 20 & 08 & 25 \\
\hline$>11$ & 10 & 12 & 05 & 18 \\
\hline \multicolumn{5}{|l|}{ Kellgren-Lawrence grade } \\
\hline 0 & 05 & 09 & 05 & 15 \\
\hline 1 & 45 & 56 & 44 & 52 \\
\hline 2 & 20 & 32 & 24 & 40 \\
\hline 3 & 07 & 10 & 07 & 13 \\
\hline 4 & 03 & 04 & 02 & 05 \\
\hline \multicolumn{5}{|l|}{ Deformity } \\
\hline No visible deformity & 30 & 45 & 29 & 45 \\
\hline Varus & 43 & 55 & 46 & 63 \\
\hline Valgus & 02 & 03 & 01 & 02 \\
\hline Knee effusion & 05 & 08 & 08 & 15 \\
\hline \multicolumn{5}{|l|}{ Previous Medication } \\
\hline NSAID & 70 & 80 & 84 & 125 \\
\hline $\mathrm{COX}-2$ & 20 & 15 & 45 & 92 \\
\hline Topical agent & 15 & 22 & 45 & 84 \\
\hline None & 10 & 0 & 0 & 0 \\
\hline Corticosteroid & 30 & 40 & 24 & 45 \\
\hline Osteoporosis medication & 25 & 24 & 26 & 40 \\
\hline Chondroprotectives & 0 & 0 & 25 & 40 \\
\hline Calcium supplements & 75 & 102 & 84 & 111 \\
\hline Vitamins & 70 & 105 & 84 & 125 \\
\hline \multicolumn{5}{|l|}{ Other } \\
\hline \multicolumn{5}{|l|}{ Previous Physical Treatment } \\
\hline Physiotherapy & 40 & 25 & 60 & 65 \\
\hline Ice or heat & 60 & 55 & 65 & 90 \\
\hline Exercise & 40 & 30 & 35 & 60 \\
\hline None & 0 & 0 & 0 & 0 \\
\hline
\end{tabular}




\begin{tabular}{|c|c|c|c|c|}
\hline Relaxation technique & & & & \\
\hline Splint & 02 & 03 & 12 & 18 \\
\hline Diet & 10 & 13 & 18 & 30 \\
\hline Yoga & 02 & 0 & 05 & 14 \\
\hline Arthroscopy & 0 & 0 & 0 & 02 \\
\hline Massage & 50 & 65 & 20 & 28 \\
\hline Local irritants application & 40 & 55 & 23 & 34 \\
\hline
\end{tabular}

OA: Osteoarthritis, NSAID: Non-steroidal anti-inflammatory drug, COX-2: Cyclooxygenase inhibitors values are presented as number (\%).

\begin{tabular}{|c|c|c|c|c|}
\hline \multirow[b]{2}{*}{ Characteristic Patients $n=400$} & \multicolumn{2}{|c|}{ Rural } & \multicolumn{2}{|c|}{ Semi-Urban } \\
\hline & $\begin{array}{l}\text { Male } \\
\mathbf{n}=\mathbf{8 0}\end{array}$ & $\begin{array}{c}\text { Female } \\
n=111\end{array}$ & $\begin{array}{c}\text { Male } \\
n=84\end{array}$ & Female $n=125$ \\
\hline Walking long distance & 76 & 98 & 68 & 95 \\
\hline Transitioning from seated to standing & 20 & 31 & 28 & 38 \\
\hline Transitioning from squatting to standing & 35 & 42 & 50 & 80 \\
\hline Cross-legged sitting & 25 & 44 & 56 & 80 \\
\hline Squatting & 20 & 18 & 48 & 78 \\
\hline Standing & 18 & 22 & 35 & 20 \\
\hline Sitting & 2 & 5 & 10 & 22 \\
\hline Walking short distance & 4 & 13 & 16 & 30 \\
\hline Sleeping & 2 & 4 & 3 & 4 \\
\hline Lying down & 5 & 7 & 6 & 12 \\
\hline Avoid using stairs because of knee pain & 20 & 35 & 40 & 70 \\
\hline Knee stiffness when waking in the morning & 3 & 05 & 12 & 38 \\
\hline Knee pain limits daily activity & 10 & 15 & 22 & 42 \\
\hline Braces/ Splints & 02 & 03 & 12 & 18 \\
\hline \multicolumn{5}{|l|}{ Ambulatory aid } \\
\hline None & 68 & 86 & 77 & 102 \\
\hline Cane & 15 & 22 & 05 & 16 \\
\hline Walker & 1 & 2 & 1 & 4 \\
\hline Crutch & 0 & 1 & 1 & 2 \\
\hline Wheelchair & 0 & 0 & 0 & 1 \\
\hline Table 3. Leve & nctio & itation & & \\
\hline
\end{tabular}

Values are presented as number (\%).

\section{RESULTS}

\section{Participant Screening}

A total of 510 patients were screened for participation in this study, of which 110 were deemed ineligible to participate in the study. The reasons for ineligibility included previous history of total knee arthroplasty in the affected knee $(20$ patients), fracture of the tibial plateau, proximal tibia, femoral condyle, distal $3^{\text {rd }}$ femur and patella (40 patients), septic infected knee (05 patients), cellulitis leg (03 patients), rheumatoid arthritis (40) and below knee amputation (02 patients). Ultimately, 400 patients met the eligibility criteria and participated in this study.

\section{DISCUSSION}

Our study findings are suggestive that symptoms of arthritis appear earlier in the patients. There is a period of remission. During that period of arthritis, they would have learnt about the different modalities of treatment they responded well with. When they had remission of knee arthritis, they followed similar treatment they had earlier. Few responded with short period of remission, most of the patients changed the modalities of treatment they were following earlier, found that they had longer period of remission with physical therapy, pain medication, calcium supplements, osteoporosis medication, changes in lifestyle, daily activities, change in occupation, use of assisted ambulation helped them to the extent that longer period of remission was satisfactory for them to say no to surgical procedures. Few patients had associated arthritis of hip, back and hand.

This revelations during study made us feel more responsible towards the social community to impart knowledge to them by awareness programmes.

Heavy weight and obesity are well-known risk factors for $\mathrm{OA}$, since they increase mechanical stress and induce systemic effects (eg, via adipokines and/or hyperglycaemia) involved in OA pathogenesis. It has been recently confirmed that in knee $\mathrm{OA}$, mechanical stress is the most important underlying mechanism. This is in contrast to hand $\mathrm{OA}$, where systemic processes appear to be most important. OA risk increases almost exponentially according to the increase in Body Mass Index (BMI).

Patients from rural areas occupation was agriculture. On initial phase of knee arthritis they received nonpharmacological treatment like branding, massage and local counter-irritants. Remission was for short period. On relapse responded well with NSAIDS prescribed by local practitioner and few received oral steroids. Patients in India are being seen by a specialist and are receiving medical care in the early stages of $\mathrm{OA}$, which goes against the common 
perception that patients in India do not receive medical treatment for early stage $\mathrm{OA}$ and thus eventually present with advanced stages of OA. ${ }^{11}$

Patients treated at our centre had longer duration of remission as they received NSAIDS, vitamins, chondroprotectives, calcium supplements, carbonate and citrate and osteoporosis medicine. Comorbid conditions were treated by respective specialist, physiotherapy electrotherapy, wax, exercises, postures, use of splints, ambulatory aids, gait training and the needy were given intraarticular steroid and viscosupplements. Osteoarthritis awareness counselling scheduled for patients helped them. Patients deferred surgery. $90 \%$ of patients were not having insurance policy, annual economy was 50,000 to 200,000 . Patients found practising physiotherapy, usage of splints, ambulatory aids, change of occupation, avoiding stressful activities, modification of activities of daily living like avoiding squatting or cross-legged sitting helped in preserving the joint function. Exercise is also beneficial as shown in a recently published randomised controlled trial in women with $\mathrm{OA}$ of the knee. ${ }^{10}$ We believe that putting as much effort into $\mathrm{OA}$ research as was seen in recent years in RA research may yield significant progress in improving quality of life for many patients with $\mathrm{OA}$.

\section{CONCLUSION}

The prevalence of OA knee was found to be $19 \%$ in rural area and 21\% in semi-urban area in Moinabad district. Prevalence of osteoarthritis of knee was higher in females in semi-urban and rural areas than in men. This is also observed because of osteoporosis in menopause women, sedentary lifestyle, older age, less educated, and treated frequently with oral steroids. Change in lifestyle, occupation and exercises helped the patients to avoid surgical intervention. Patients in India are usually treated by a specialist and are receiving medical care in the early stages of $\mathrm{OA}$, which goes against the common perception that patients in India do not receive medical treatment for early stage $\mathrm{OA}$ and thus eventually present with advanced stages of OA. ${ }^{11}$

\section{REFERENCES}

[1] Sharma MK, Swami HM, Bhatia V, et al. An epidemiological study of correlates of osteo-arthritis in geriatric population of UT Chandigarh. Indian J Community Med 2007;32(1):77-8.
[2] Atukorala I, Makovey J, Lawler L, et al. Is there a dose response relationship between weight loss and symptom improvement in persons with symptomatic knee osteoarthritis? Osteoarthritis and Cartilage 2014;22(Suppl 1):S50-S51.

[3] Busija L, Bridgett L, Williams SR, et al. Osteoarthritis. Best Pract Res Clin Rheumatol 2010;24(6):757-68.

[4] Cross M, Smith E, Hoy D, et al. The global burden of hip and knee osteoarthritis: estimates from the Global Burden of Disease 2010 study. Ann Rheum Dis 2014;73(7):1323-30.

[5] Visser AW, de Mutsert R, le Cessie S, et al. The relative contribution of mechanical stress and systemic processes in different types of osteoarthritis: the NEO study. Ann Rheum Dis 2014: p. 1-6. Published Online First: 20 May 2014. doi:10.1136/annrheumdis-2013205012.

[6] Glass N, Segal NA, Sluka KA, et al. Examining sex differences in knee pain: the multicentre osteoarthritis study. Osteoarthritis Cartilage 2014;22(8):1100-6.

[7] Rosemann T, Laux G, Szecsenyi J. Osteoarthritis: quality of life, comorbidities, medication and health service utilization assessed in a large sample of primary care patients. J Orthop Surg Res 2007;2:12

[8] Oliveria SA, Felson DT, Reed JI, et al. Incidence of symptomatic hand, hip and knee osteoarthritis among patients in a health maintenance organization. Arthritis Rheum 1995;38(8):1134-41.

[9] Bijlsma JW, Berenbaum F, Lafeber FP. Osteoarthritis: an update with relevance for clinical practice. Lancet 2011;377(9783):2115-26.

[10] Jorge RTB, de Souza MC, Chiari A, et al. Progressive resistance exercise in women with osteoarthritis of the knee: a randomized controlled trial. Clin Rehabil 2015;29(3):234-43.

[11] Sancheti P, Shetty VD, Dhillon MS, et al. India-based knee osteoarthritis evaluation (iKare): a multi-centre cross-sectional study on the management of knee pain and early osteoarthritis in India. Clinics in Orthopedic Surgery 2017;9(3):286-94. www.ecios.org 